\title{
Subarachnoid Hemorrhage Caused by Aspergillus Aneurysm as a Complication of Transcranial Biopsy of an Orbital Apex Lesion
}

\author{
-Case Report-
}

\author{
Yoshikazu OKadA, Takeshi SHIMA*, Masahiro NiSHIDA*, Kanji YAMANE*, \\ and Akira YosHIDA** \\ Department of Neurosurgery, Shimane Medical University, Izumo, Shimane; Departments \\ of ${ }^{*}$ Neurosurgery and ${ }^{* *}$ Intensive Care Medicine, Chugoku Rousai Hospital, \\ Kure, Hiroshima
}

\begin{abstract}
A 62-year-old male complaining of unilateral visual disturbance and pain in the involved eye had a small mass at the right orbital apex which was identified as an Aspergillus granuloma by transcranial biopsy. One month later, the patient became comatose because of fatal subarachnoid hemorrhage due to a newly developed aneurysm. Autopsy showed a ruptured aneurysm on the right internal carotidposterior communicating artery. Histological examination demonstrated prominent Aspergillus invasion of the arterial wall. Aspergillus infection must be taken into consideration in patients with orbital apex syndrome, which may lead to serious cerebrovascular consequences. If sino-orbital lesions are detected by neuroimaging techniques, biopsy using an extradural approach should be performed to obtain a definitive diagnosis.
\end{abstract}

Key words: Aspergillus, de novo aneurysm, subarachnoid hemorrhage, visual disturbance, steroid

\section{Introduction}

The increasing use of corticosteroids and immunosuppressive agents has led to an increase in fungal infections. ${ }^{17,34,35)}$ Aspergillus is one of the most common causes of fungal infection in the central nervous system. Cerebral Aspergillus infection is characterized by patches of hemorrhagic necrosis in the acute or subacute phase and granulomatous inflammation in the chronic phase. ${ }^{21.26,27,37)}$ The five major forms of manifestation of aspergillosis in the central nervous system are: meningitis, meningoencephalitis, abscess, single solid granuloma without abscess formation, and vascular disease. ${ }^{27,37]}$

Cerebrovascular lesions due to fungal infection mainly occur due to direct invasion of the arterial wall by fungi from an intraluminal embolus that extends its hyphae outward, or from fungal meningitis that penetrates the adventitia. ${ }^{21,22,27,37)}$ The resultant

Received October 13, 1997; Accepted March 27, 1998 fungal arteritis may cause thrombosis of the inflamed vessel associated with hemorrhagic cerebral infarction or ill-defined abscesses, immediate vessel rupture associated with massive hemorrhage, or focal necrosis of the elastica associated with diffuse expansion of the vessel or a saccular intracranial fungal aneurysm. ${ }^{26,27,32)}$ Subarachnoid hemorrhage (SAH) secondary to rupture of fungal aneurysms is rare, but has been fatal in all reported cases. We treated a patient with a transcranial biopsy of a small lesion at the right orbital apex, which was complicated by rupture of a de novo Aspergillus aneurysm resulting in fatal SAH.

\section{Case Report}

A 62-year-old male with a 2-month history of visual disturbance and pain in the right retro-orbital and frontotemporal regions was admitted to our hospital. He had been healthy for the past 20 years except for mild diabetes mellitus.

On admission, his visual acuity was 0.4 in the right 


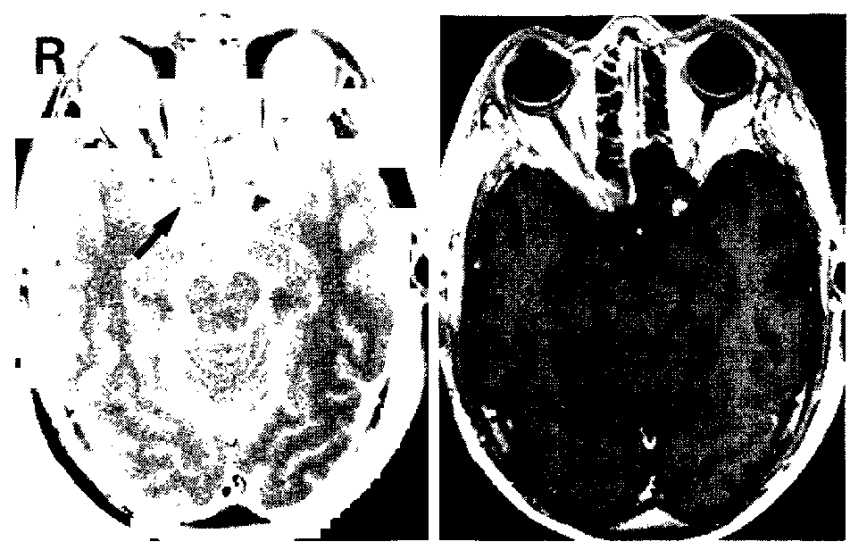

Fig. 1 Magnetic resonance images demonstrating a small mass at the tip of the right anterior clinoid process (arrow) (left), enhanced by gadolinium (right).
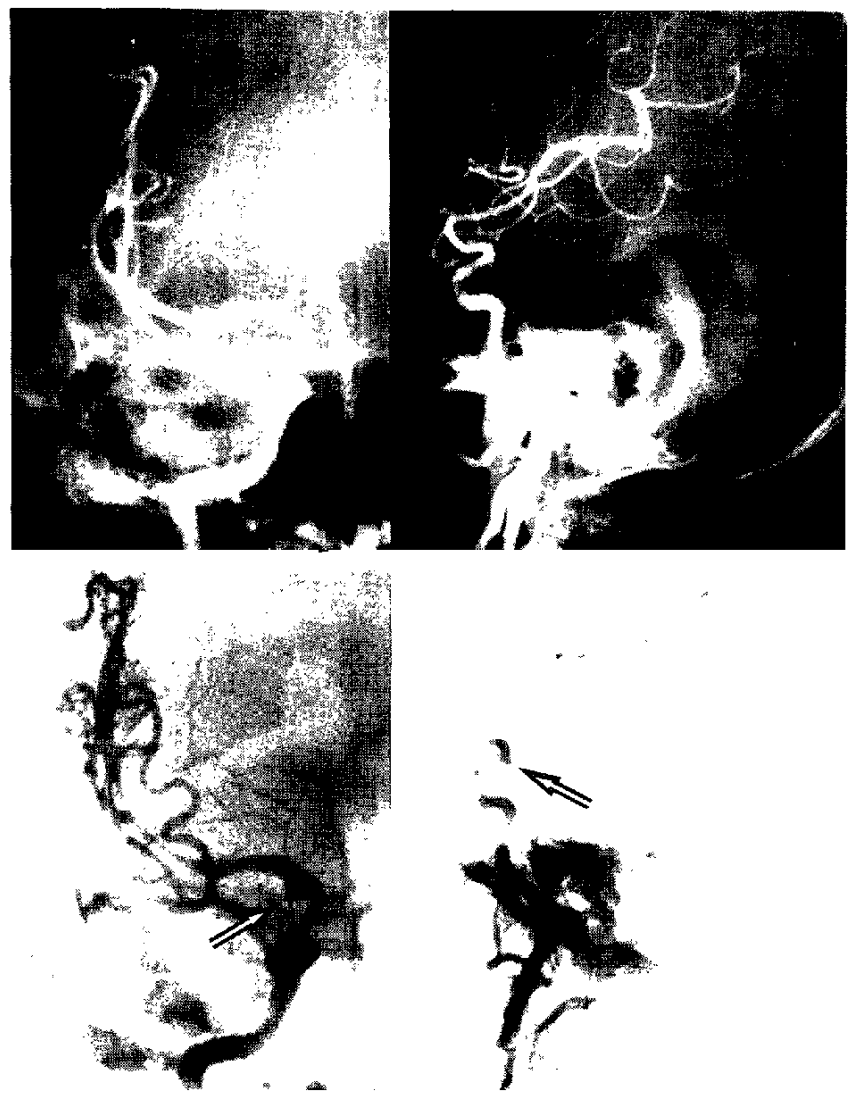

Fig. 2 Cerebral angiograms, performed on November 10,1991 revealing no vascular lesions (upper), and on April 7, 1992 showing an aneurysm on the right internal carotidposterior communicating artery (arrow) (lower).
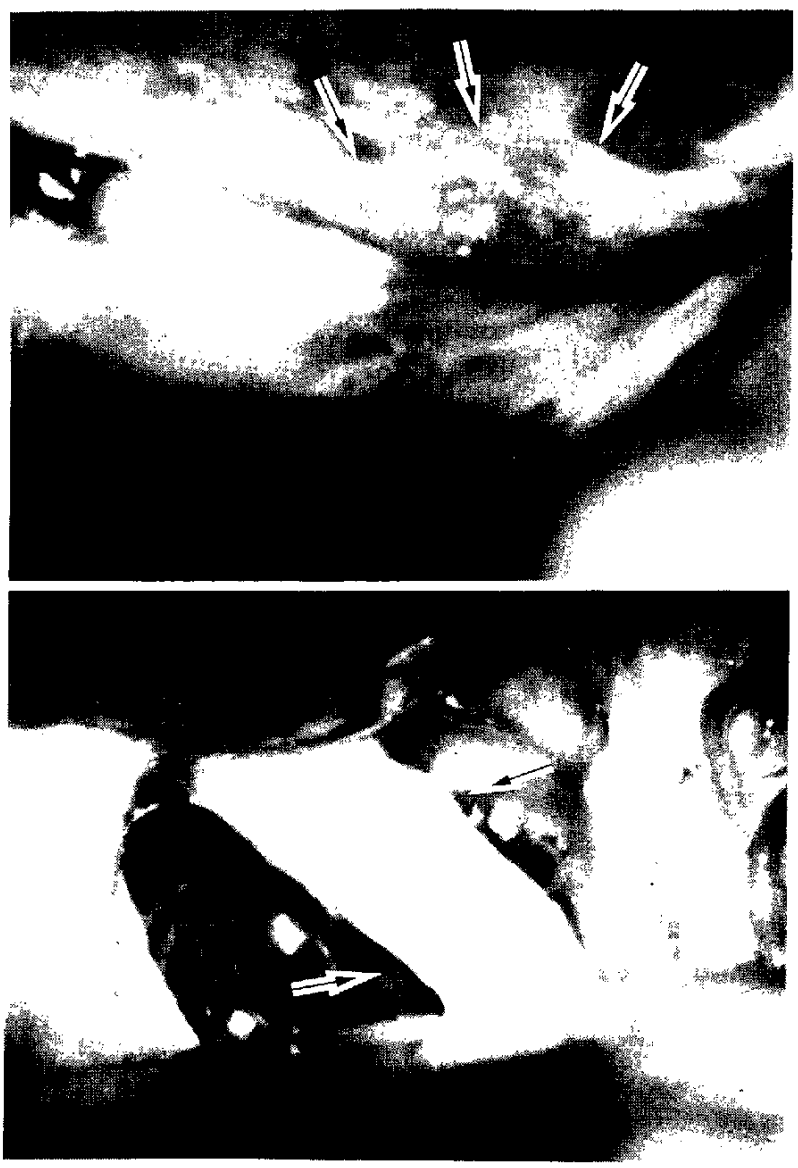

Fig. 3 Intraoperative photographs, showing a small bulging hypervascular mass at the anterior clinoid process (arrows) (upper), but no other lesion at the optic nerve, the internal carotid artery, or the posterior communicating artery (arrows) (lower).

eye and 1.5 in the left eye. Computed tomography (CT) of the head showed no mass near the right optic nerve. However, magnetic resonance (MR] imaging showed a small lesion at the right orbital apex (Fig. 1). Cerebral angiography showed no vascular lesions such as an aneurysm (Fig. 2 upper). Results of examination of cerebrospinal fluid were normal.

The patient was treated with steroids $(8 \mathrm{mg} /$ day of betamethasone and $10 \mathrm{mg} /$ day of prednisolone) from November 12, 1991 to February 4, 1992. This steroid regimen relieved his pain, but did not improve his visual acuity, which deteriorated rapidly to 0.05 by day 5 , and he became blind on January 30,1992 . He developed right oculomotor nerve palsy on February 24,1992 . Since the symptoms developed very rapidly and seemed to be closely related with the lesion at the right orbital apex, a transcranial biopsy was performed on March 16, 1992. 

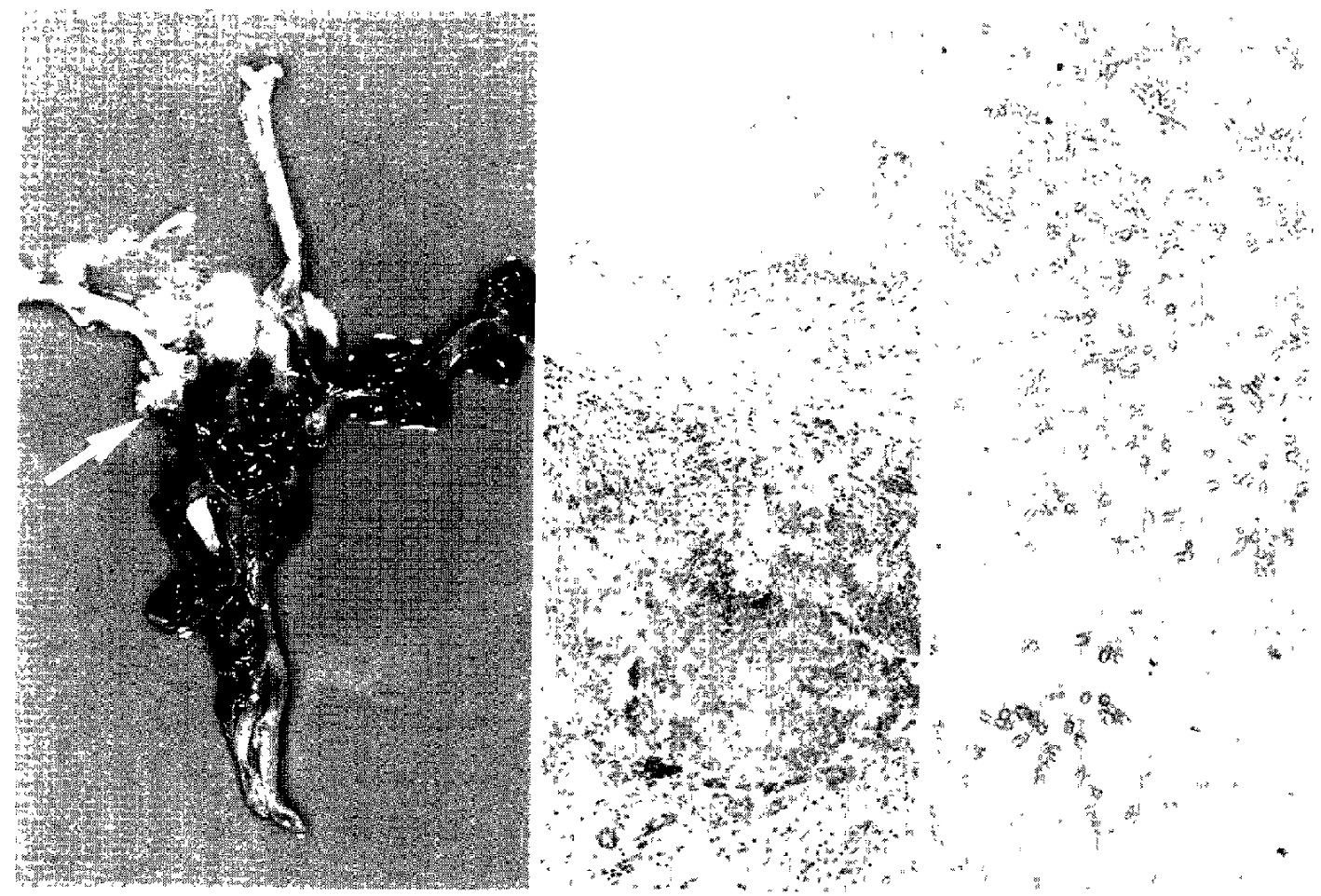

Fig. 4 Photograph of the main cerebral vessels confirming subarachnoid hemorrhage due to ruptured aneurysm (arrow) (left). Photomicrographs of the ruptured site showing numerous inflammatory infiltrating cells with Aspergillus invasion (HE stain, center: $\times 25$, right: $\times 100$.

The dura mater of the right anterior clinoid process was thick and hypervascular (Fig. 3 upper), but no lesion was observed at the optic nerve and the internal carotid artery (Fig. 3 lower). After the dura was excised, a yellowish-white granulomatous lesion was observed between the optic nerve and the anterior cavernous sinus. Small specimens of the granulomatous lesion showed the presence of Aspergillus. The excised dura was repaired using the temporal muscle and fascia.

Postoperatively, antibiotic therapy (fluconazole $100 \mathrm{mg} /$ day] was performed for 10 days. His course was uneventful with no infectious signs and symptoms, but blindness and oculomotor nerve palsy in the right eye persisted. On April 7, 1992, the patient suddenly became comatose. CT showed serious SAH (Hunt and Hess grade V). Right carotid angiography revealed a newly developed aneurysm (approximately $5 \mathrm{~mm}$ in diameter) on the internal carotid-posterior communicating artery, which was believed to be the source of the SAH (Fig. 2 lower). His consciousness did not improve despite a variety of conservative treatments and he died on April 12, 1992.

Autopsy found diffuse swelling with thick SAH at the base of the brain. Dissection of the cerebral ves- sels revealed a ruptured aneurysm, $5 \mathrm{~mm}$ in diameter, on the right internal carotid-posterior communicating artery (Fig. 4 left). The optic nerves were surrounded by yellowish pus, which extended to the biopsied area of the anterior clinoid process. However, there was no pus in the sphenoid sinus. Histological examination found extensive destruction of the arterial wall with dense inflammatory cell infiltration through the wall of the aneurysm and its neighborhood (Fig. 4 center). The aneurysm was characterized by the destruction of the elastica interna and media, and numerous infiltrating inflamatory cells in the aneurysm wall. A number of branching septate hyphae, morphologically identifiable as Aspergillus, were observed in these regions (Fig. 4 right). Aspergillosis was also seen in the mass of the right anterior clinoid process, but not in the sphenoid sinus and other organs.

\section{Discussion}

Our present patient died of SAH due to a de novo aneurysm resulting from cerebral Aspergillus infection as a complication of transcranial biospy of the lesion at the orbital apex.

$\mathrm{SAH}$ due to ruptured fungal aneurysm is 
Tahle 1 Cases of cerebral aneurysm of fungal origin

\begin{tabular}{|c|c|c|c|c|c|c|}
\hline $\begin{array}{l}\text { Case } \\
\text { No. }\end{array}$ & Author (Year) & $\begin{array}{l}\text { Age, } \\
\text { Sex }\end{array}$ & $\begin{array}{c}\text { Site of } \\
\text { aneurysm(s) }\end{array}$ & Organism & $\begin{array}{l}\text { Route of } \\
\text { infection* }\end{array}$ & $\begin{array}{l}\text { Associated } \\
\text { disease(s) }\end{array}$ \\
\hline 1 & Morriss and Spock $(1970)^{23)}$ & $11, \mathrm{M}$ & ICA & Penicillium & 2 & sinusitis \\
\hline 2 & Davidson and Robertson (1971) & $75, \mathrm{M}$ & $\mathrm{BA}$ & Aspergillus & 2 & sinusitis \\
\hline 3 & Visudhiphan et al. (1973) & $13, \mathrm{M}$ & $\mathrm{BA}$ & Aspergillus & 3 & craniopharyngioma \\
\hline 4 & & $5, \mathrm{M}$ & $\mathrm{MCA}$ & Aspergillus & 1 & pneumonia \\
\hline 5 & Sakaki et al. $(1975)^{28 \mid}$ & $26, M$ & ICA & Aspergillus & 3 & AVM \\
\hline 6 & Horten et al. $(1976)^{13 i}$ & $17, \mathrm{~F}$ & $\mathrm{MCA}, \mathrm{ACA}$ & Aspergillus & 1 & aortic stenosis \\
\hline 7 & Glass et al. $(1978)^{7)}$ & $4, \mathrm{~F}$ & $\mathrm{ACA}$ & Phycomycetes & 1 & pneumonia \\
\hline 8 & Ahuja et al. $(1978)^{11}$ & $18, \mathrm{M}$ & ICA & Aspergillus & 2 & sinusitis \\
\hline 9 & Ho $(1979)^{12 \mid}$ & $48, F$ & $A \operatorname{com} A$ & Phycomycetes & 2 & DM, sinusitis \\
\hline 10 & Scully et al. $(1979)^{29]}$ & $66, \mathrm{M}$ & SCA & Candida & 1 & stomach cancer \\
\hline 11 & Goldman et al. $(1979)^{8 !}$ & $16, F$ & $\mathrm{BA}$ & Candida & 2 & SLE, sinusitis \\
\hline 12 & Mielke et al. $(1981)^{22]}$ & $58, \mathrm{~F}$ & $\mathrm{BA}, \mathrm{ICA}$ & Aspergillus & 3 & pituitary tumor \\
\hline 13 & Partridge and Chin $(1981)^{24)}$ & $18, M$ & VA & Aspergillus & 3 & periorbital tumor \\
\hline 14 & Bullock et al. (1981) $)^{4]}$ & $54, \mathrm{M}$ & $\mathrm{ACA}$ & Candida & 1 & endocarditis \\
\hline 15 & Shimosaka and Waga $(1983)^{32)}$ & $23, \mathrm{M}$ & MCA & Chromoblastomycosis & 3 & orbitofrontal tumor \\
\hline 16 & Ichikawa et al. $(1984)^{14 j}$ & $72, \mathrm{M}$ & ICA & Aspergillus & 1 & pneumonia \\
\hline 17 & Walsh et al. $(1985)^{971}$ & $64, \mathrm{~F}$ & PCA & Aspergillus & 1 & Cushing's syndrome \\
\hline 18 & Kikuchi et al. (1985) & $61, \mathrm{M}$ & ACA & Phycomycetes & 3 & cerebral aneurysm \\
\hline 19 & Vu et al. $(1986)^{38)}$ & $62, \mathrm{M}$ & $\mathrm{ACA}$ & Aspergillus & 1 & hemodialysis \\
\hline 20 & Hadley et al. $(1987)^{10]}$ & $20, \mathrm{~F}$ & ICA, BA & Candida & 1 & pneumonia \\
\hline 21 & Asari et al. $(1988)^{2)}$ & $48, \mathrm{M}$ & $\mathrm{ACA}$ & Aspergillus & 3 & cerebral aneurysm \\
\hline 22 & Scully et al. $(1988)^{30)}$ & $27, \mathrm{M}$ & $\mathrm{BA}$ & Aspergillus & 1 & leukemia \\
\hline 23 & Piotrowski et al. $(1990)^{25)}$ & $40, F$ & ICA, VA & Aspergillus & 3 & cerebral aneurysm \\
\hline 24 & Barrow amd Prats (1990) ${ }^{31}$ & $4, \mathrm{M}$ & BA, VA & Aspergillus & 3 & brain tumor \\
\hline 25 & lihara et al. $(1990)^{15)}$ & $78, \mathrm{~F}$ & $\mathrm{BA}$ & Aspergillus & 2 & sphenoid tumor \\
\hline 26 & Komatsu et al. $(1991)^{18 j}$ & $61, F$ & ICA & Aspergillus & 3 & Rathke's cleft cyst \\
\hline 27 & Masago et al. (1992) & $75, \mathrm{~F}$ & MCA & Aspergillus & 1 & bronchopneumonia \\
\hline 28 & Takeshita et al. (1992) ${ }^{33 !}$ & $39, \mathrm{M}$ & SCA & Aspergillus & 3 & facial spasm \\
\hline 29 & Kurino et al. $(1994)^{19)}$ & $63, \mathrm{M}$ & VA & Aspergillus & 2 & temporal base granuloma \\
\hline 30 & Present case & $62, \mathrm{M}$ & ICA & Aspergillus & 3 & anterior clinoid lesion \\
\hline
\end{tabular}

${ }^{*}$ 1: Hematogenous dissemination from a remote extracranial site ${ }^{37)} 2$ : extension from a contiguous cranial foci such as the nasal cavity and the paranasal sinuses, ${ }^{111} 3$ : direct introduction in patients who developed fungal infection after neurosurgical procedures. ${ }^{6}$ ) ACA: anterior cerebral artery, AcomA: anterior communicating artery, AVM: arteriovenous malformation, BA: basilar artery, DM: diabetes mellitus, ICA: internal carotid artery, MCA: middle cerebral artery, PCA: posterior cerebral artery, SCA: superior cerebral artery, SLE: systemic lupus erythematosus, VA: vertebral artery.

rare and has been fatal in all previous 29 cases of ruptured fungal aneurysm [Table 1). ${ }^{1-5,7,8,10,12-16,18-20,22-25,28-30,32,33,35-37)}$ Fungal aneurysms commonly arise from the major cerebral arteries and are large ( 5 to $10 \mathrm{~mm}$ in diameter). ${ }^{27)}$ Fifteen of the 30 aneurysms were located on the internal carotid and/or basilar artery. Aspergillus was the common causative organism (21 cases) followed by Candida (4 cases). The causative organism may reach the central nervous system by three different routes: Hematogenous dissemination from a remote extracranial site ${ }^{37]}$ extension from a contiguous cranial foci such as the nasal cavity and the paranasal sinuses, ${ }^{11)}$ and direct introduction in patients who developed fungal infection after neurosurgical procedures. ${ }^{6)}$ The first route infection was suspected in 11 cases, the second route in seven, and the third route in 12 . Patients suffered ruptured aneurysms approximately 2 months (4 days-15 months) after the direct neurosurgical procedures. Four of the 12 cases had operations for mass lesions located around orbital apex region, which had fungal infection.

Fungal infections generally occur in debilitated patients with predisposing factors such as routine administration of steroids and immunosuppressive agents, but rarely occurs in the orbit and/or cavernous sinus region of healthy individuals following a contiguous infection in the paranasal sinuses. ${ }^{17,27,34,37)}$ In the latter, high-resolution neuroimaging techniques such as CT and MR imaging may be useful for visualizing lesions. ${ }^{\text {9) }}$ However, some inflammatory lesions cannot be distinguished by neuroimaging techniques. Consequently, histological examination is required to confirm Aspergillus infection. The patient and previous cases of ruptured fun- 
gal aneurysm infected via neurosurgical procedures indicate that direct intracranial introduction of fungus may cause fatal vascular lesions. Therefore, extradural approaches such as transsphenoidal, transnasal, and transorbital biopsy should be used to establish the histological diagnosis for a mass lesion in the cavernous sinus, orbital apex, and/or paranasal sinus. A patient with Aspergillus granuloma involving paranasal sinuses and cavernous sinus to occlude the internal carotid artery underwent transsphenoidal biopsy and successfully treated. ${ }^{311}$ Ruptured fungal aneurysms are associated with extremely high mortality, so aggressive attempts to obtain an early diagnosis of sino-orbital lesions by neuroimaging techniques and extradural biopsy essential to prevent fungal invasion into the intracranial vessels. If an intracranial fungal infection is suspected during the surgical ргеparations, appropriate medical therapy using antifungal agents should be maintained for at least 2 months and follow-up studies of cerebral vessels performed by noninvasive methods such as MR angiography.

\section{References}

1) Ahuja GK, Jain N, Vijayaraghavan M, Roy S: Cerebral mycotic aneurysm of fungal origin. J Neurosurg 49: 107-110, 1978

2) Asari S, Nishimoto A, Murakami M: [A rare case of cerebral aspergillus aneurysm at the site of temporary clip application]. No Shinkei Geka 16: 1079-1082, 1988 (Jpn, with Eng abstract)

3) Barrow DL, Prats AR: Infectious intracranial aneurysms: Comparison of groups with and without endocarditis. Neurosurgery 27: 562-573, 1990

4) Bullock R, van Dellen JR, van den Heever CM: Intracranial mycotic aneurysm. A review of 9 cases. $S$ Afr Med J 60: 970-973, 1981

5) Davidson P, Robertson DM: A true mycotic (Aspergillus) aneurysm leading to fatal subarachnoid hemorrhage in a patient with hereditary hemorrhagic telangiectasia. J Neurosurg 35: 71-76, 1971

6] Galassi E, Pozzati E, Poppi M, Vinci A: Cerebral aspergillosis following intracranial surgery. $J$ Neurosurg 49: 308-311, 1978

7) Glass EC, Stadalnik RC, Barnett CA: Ventricular visualization on brain scan with intracranial hemorrhage in disseminated phycomycosis. Clin Nucl Med 3: 429-431, 1978

8) Goldman JA, Fleischer AS, Leifer W, Parent A, Schwarzman SW, Raggio J: Candida albicans mycotic aneurysm associated with systemic lupus erythematosus. Neurosurgery 4: 325-328, 1979

9) Grossman RI, Davis KR, Taveras JM, Beal MF, O'Carroll CP: Computed tomography of intracranial aspergillosis. J Comput Assist Tomogr 5: 646-650, 1981

10) Hadley MN, Martin NA, Spetzler RF, Johnson PC:
Multiple intracranial aneurysms due to coccidioides immitis infection. J Neurosurg 66: 453-456, 1987

11) Hedges TR, Leung L-SE: Parasellar and orbital apex syndrome caused by aspergillosis. Neurology 26: 117-120, 1976

12) Ho K-L: Acute subdural hematoma and intracerebral hemorrhage. Arch Otolaryngol 105: 279-281, 1979

13) Horten BC, Abbott GF, Porro RS: Fungal aneurysms of intracranial vessels. Arch Neurol 33: 577-579, 1976

14) Ichikawa $K$, Tsutsumi $A$, Hiyama $K$, Komure $O$, Fujioka A: [An autopsy case of intracranial fungal (Aspergillus) mycotic aneurysm]. Rinsho Shinkeigaku 24: 567-570, 1984 (Jpn, with Eng abstract)

15) Iihara K, Makita $Y$, Nabeshima $S$, Tei T, Keyaki A, Nioka H: Aspergillosis of the central nervous system causing subarachnoid hemorrhage from mycotic aneurysm of the basilar artery. Case report. Neurol Med Chir (Tokyo) 30: 618-623, 1990

16) Kikuchi K, Watanabe K, Sugawara A, Kowada M; Multiple fungal aneurysms: Report of a rare case implicating steroid as predisposing factor. Surg Neurol 24: 253-259, 1985

17) Kim DG, Hong SC, Kim HJ, Chi JG, Han MH, Choi KS, Han HH: Cerebral aspergillosis in immunologically competent patients. Surg Neurol 40: 326-331, 1993

18) Komatsu $Y$, Narushima K, Kobayashi E, Tomono $Y$, Nose T: Aspergillus mycotic aneurysm. Case report. Neurol Med Chir (Tokyo) 31: 346-350, 1991

19) Kurino M, Kuratsu J, Yamaguchi T, Ushio Y: Mycotic aneurysm accompanied by aspergillus granuloma: A case report. Surg Neurol 42: 160-164, 1994

20) Masago A, Fukuoka $H$, Yoshida T, Majima K, Tada T, Nagai H: Intracranial mycotic aneurysm caused by Aspergillus. Case report. Neurol Med Chir (Tokyo) 32: 904-907, 1992

21) McKee EE: Mycotic infection of brain with arteritis and subarachnoid hemorrhage. Am J Clin Pathol 20: 381-384, 1950

22) Mielke B, Weir B, Oldring D, von Westrap C: Fungal aneurysm: Case report and review of the literature. Neurosurgery 9: 578-582, 1981

23) Morriss FH Jr, Spock A: Intracranial aneurysm secondary to mycotic orbital and sinus infection. Am J Dis Child 119: 357-362, 1970

24) Partridge BM, Chin ATL: Cerebral aspergilloma. Postgrad Med J 57; 439-442, 1981

25) Piotrowski WP, Pilz P, Chuang I-H: Subarachnoid hemorrhage caused by a fungal aneurysm of the vertebral artery as a complication of intracranial aneurysm clipping. J Neurosurg 73: 962-964, 1990

26) Price DL, Wolpow ER, Richardson EP: Intracranial phycomycosis: A clinicopathological and radiological study. J Neurol Sci 14: 359-375, 1971

27) Rowe FA, Youmans JR, Lec HJ, Cabieses F: Parasitic and fungal diseases of the central nervous system, in Youmans JR (ed): Neurological Surgery. Philadelphia, Saunders, 1982, pp 3366-3440

28) Sakaki H, Kikuchi H, Kose K, Kawai S, Karasawa J, Manabe T, Yoshida Y, Matsuda I: [Case of cerebral 
aneurysm due to aspergillus angiitis]. Rinsho Hoshasen 20: 95-96, 1975 (Jpn)

29) Scully RE, Galdabini JJ, McNeely BU: Case records of the Massachusetts General Hospital. Weekly clinicopathological exercises. N Engl J Med 301: 3442, 1979

30) Scully RE, Mark EJ, McNeely WF, McNeely BU: Case records of the Massachusetts General Hospital. Weekly clinicopathological exercises. $N$ Engl J Med 318: 427-440, 1988

31) Sekhar LN, Dujovny M, Rao GR: Carotid-cavernous sinus thrombosis caused by Aspergillus fumigatus. $J$ Neurosurg 52: 120-125, 1980

32) Shimosaka S, Waga S: Cerebral chromoblastomycosis complicated by meningitis and multiple fungal aneurysms after resection of a granuloma. Case report. J Neurosurg 59: 158-161, 1983

33) Takeshita M, Izawa M, Kubo O, Tanikawa T, Onda $\mathrm{H}$, Wanifuchi $\mathrm{H}$, Tamura $\mathrm{Y}$, Kagawa M: Aspergillotic aneurysm formation of cerebral artery following neu- rosurgical operation. Surg Neurol 38: 146-151, 1992

34] Torre-Cisneros J, Lopez OL, Kusne S, Marotomez AJ, Starzl TE, Simmons RL, Martin M: CNS aspergillosis in organ transplantation: a clinicopathological study. J Neurol Neurosurg Psychiatry 56: 188-193, 1993

35) Visudhiphan P, Bunyaratavej S, Khantanaphar S: Cerebral aspergillosis. Report of three cases. J Neurosurg 38: 472-476, 1973

36) Vu N, Kim RC, Choi BH: Aspergillus cerebral arterial aneurysm formation complicating hemodialysis. Surg Neurol 25: 582-586, 1986

37) Walsh TJ, Hier DB, Caplan LR: Aspergillosis of the central nervous system: Clinicopathological analysis of 17 patients. Ann Neurol 18: 574-582, 1985

Address reprint requests to: Y. Okada, M.D., Department of Neurosurgery, Shimane Medical University, 89-1 Enya-cho, Izumo, Shimane 693-8501, Japan. 